\title{
A Inflação de Preços em Discussão na Sala de Aula de Matemática
}

\section{Márcio Carlos Vital}

Núcleo de Investigação, Divulgação e Estudos em Educação Matemática / NIDEEM - UFJF

mc.vital@hotmail.com

\section{Resumo}

As tarefas apresentadas a seguir foram elaboradas com o intuito de promover na sala de aula um ambiente capaz de estimular os alunos a analisar e discutir sobre inflação de preços. O conjunto de tarefas foi elaborado, originalmente, para alunos do $8^{\circ}$ ou $9^{\circ}$ ano do Ensino Fundamental.

Palavras-chave: Inflação de preços. Educação Financeira. Produção de tarefas. Ensino Fundamental.

\section{The Discussion Prices Inflation in the Mathematics Classroom}

\begin{abstract}
The following tasks were elaborated in order to promote an environment able to encourage students to analyze and discuss about price inflation in the classroom. The set of tasks was elaborated, originally, for 8th or 9th grade students of elementary school.
\end{abstract}

Keywords: Price inflation. Financial Education. Task production. Elementary School.

\section{Tarefas propostas}

A primeira tarefa tem como objetivo introduzir o tema inflação de preços a partir do que os alunos podem dizer sobre o tema de modo a estimulá-los a falar sobre o assunto.

\section{Tarefa 1: Pergunta disparadora}

\section{Inflação de Preços}

As tarefas a seguir têm como objetivo esclarecer o que é inflação e como ela influencia na nossa vida, da nossa família e de nosso país.

Antes de começar nossas leituras, gostaria de saber o que você sabe dizer sobre inflação de preços. 
A segunda tarefa tem como objetivo expor a caracterização de inflação de preços e, principalmente, verificar nas falas dos alunos as diferentes interpretações em relação ao texto apresentado. Para isso, realizamos dois questionamentos para os alunos responderem de forma individual para posterior debate com toda a turma.

\section{Tarefa 2: O que é inflação de preços? \\ A inflação de preços ou simplesmente inflação é o processo de aumento contínuo e generalizado de preços dos bens e serviços negociados em um país. Contínuo porque o aumento dos preços ocorre ao longo de meses, anos e até décadas. Generalizado porque ele acontece no preço da maioria dos bens e serviços, tais como, alimentos, automóveis, aluguéis, passagens de ônibus, gasolina, cafezinho e pão francês. Estas duas características são importantes para se dizer que houve inflação.}

\section{Para discutir:}

Considerando o texto anterior, responda:

a) Se há um aumento de preços num dado mês por algum motivo e há estabilidade de preços nos meses seguintes, podemos caracterizar inflação?

b) Se apenas os preços das hortaliças e frutas aumentam num período do ano enquanto o preço da maioria dos demais produtos permanece inalterado, podemos caracterizar inflação?

O professor poderá utilizar aproximadamente 50 minutos para realizar a aplicação destas duas tarefas. Sugerimos a possibilidade de não apresentar aos alunos nenhum detalhamento ou explicação sobre o tema, ou seja, realizar o mínimo de intervenção possível. Propomos ainda que as anotações dos alunos sejam recolhidas e analisadas. Com esta atitude o professor poderá encontrar elementos que não estavam presentes nas falas dos alunos durante os debates e que poderão auxiliálo a tomar decisões em relação às intervenções necessárias antes de apresentar as tarefas seguintes.

A tarefa 3 coloca em discussão alguns fatores que ocasionam a inflação de preços na economia de um país. Apresentamos somente três itens, veja abaixo:

\section{Tarefa 3: Quais as causas da inflação?}

Uma inflação de preços é causada por vários fatores, entre eles:

- O aumento da quantidade de dinheiro em circulação num país gera inflação. Pois quando ocorre esse aumento, a população tem maior poder aquisitivo e consome mais. Mas o que parece positivo, num primeiro momento, pode esconder um problema. Se o consumo é muito alto, pode haver escassez de produtos no mercado e, 
com o crescimento da procura, eles aumentam de preço. Com os preços em alta, a população perde o poder aquisitivo, ou seja, pode comprar cada vez menos.

- A inflação de preços pode ser gerada por um conflito em uma região do mundo. Por exemplo, uma guerra no Oriente Médio pode disparar o preço do petróleo vendido para vários países do mundo. Como o preço do petróleo influencia o preço de vários outros produtos e serviços, pode ocorrer inflação.

- A inflação de preços pode ser gerada por fatores climáticos num país.

\section{Para discutir:}

a) Se o governo brasileiro anunciar que o salário mínimo aumentará cinco vezes em relação ao valor atual, isso poderia influenciar na inflação?

b) O aumento do preço da gasolina pode influenciar nos gastos de uma família que não possui carro ou moto?

c) Que fatores climáticos podem influenciar na inflação de um país e por que isso ocorre?

No primeiro e segundo fatores que podem acarretar no aumento de preços decidimos fazer uma descrição, ou seja, detalhar o que está por traz dos aumentos de preços. E, com os questionamentos (a) e (b) podemos verificar o que os alunos entenderam destas duas primeiras descrições e da caracterização de inflação apresentada na tarefa 2. Contudo, não realizamos esta descrição para o terceiro item, deixamos para que os alunos apresentassem, ao responder o questionamento (c), exemplos de aumentos de preços relacionados diretamente aos fatores climáticos.

Dando continuidade à discussão, a tarefa 4 traz as principais consequências da inflação para a vida das pessoas e para a economia de um país. O tema é sugerido para leitura e posterior discussão com a turma:

\section{Tarefa 4: Quais as consequências da inflação?}

As principais consequências da inflação para a vida das pessoas e para o país são:

- Desvalorização da moeda do país, ou seja, a redução do poder de compra desse dinheiro.

Com a inflação elevada, a moeda vai perdendo seu valor com o passar do tempo, e os consumidores (por exemplo, os trabalhadores que recebem salário mínimo) que não têm reajustes constantes não conseguem comprar os mesmos produtos com o mesmo valor anterior, porque estes sofrem reajustes constantes.

- Alta da moeda de outros países e aumento do preço dos importados.

Quando a moeda de um país desvaloriza por causa da inflação, a dos outros países (principalmente o dólar e o euro) faz o movimento inverso, isto é, valoriza em relação 
à moeda desse país. Se este país com inflação elevada é muito dependente de importações como, por exemplo, de petróleo, carros, trigo, os produtos importados aumentam de preço, situação que alimenta ainda mais a alta da inflação.

- Criação de um ambiente de incertezas

A inflação cria uma enorme incerteza nas pessoas e na economia do país. A pessoa não pode assumir crédito porque não sabe como será sua renda no futuro. Dificulta o planejamento financeiro familiar. Para o país, ela dificulta o cálculo econômico e cria ineficiência, pois prejudica a tomada de decisão num ambiente de incerteza.

- Clima econômico desfavorável.

Um país que possui inflação alta é visto no mercado internacional com desconfiança e, portanto, de forma negativa. Os grandes investidores e as empresas evitam fazer investimentos produtivos de médio e longo prazos nestes países, pois sabem que a inflação alta é um indicativo de economia com problemas.

- Aumento do desemprego.

Países que não conseguem controlar a inflação sofrem, a longo prazo, com o aumento das taxas de desemprego. Isto acontece porque ocorre uma diminuição significativa no setor produtivo.

\section{Para discutir:}

Imagine que o Brasil estivesse vivendo num período de inflação alta. Analise a atitude de alguns brasileiros marcando $B$ se for uma boa atitude, $\mathrm{R}$ se for ruim ou $\mathrm{P}$ se for péssima. Considere as consequências da inflação para a vida das pessoas e para o país apresentadas anteriormente.

Os avós de Ana e Ricardo estão comprando dólar para levá-los à Disney, nos Estados Unidos, daqui a um ano.

O pai de Rodrigo vai pedir demissão do seu trabalho porque quer mudar de emprego.

O pai de Lucas decidiu comprar a casa própria financiada em 48 meses, e com isso deixar de pagar aluguel.

O pai de Rodrigo deseja dar à sua mãe uma máquina que lava e seca de cor vermelha, ele vai importá-la dos Estados Unidos.

A mãe de Lucas sugeriu a seu pai adiar a reforma da casa para o ano seguinte.

Os pais de Rodrigo estão juntando dinheiro para uma viagem e estão guardandoo em casa.

Apesar de se tratar de um tema complexo decidimos discuti-lo principalmente por um motivo: os alunos nesta faixa etária não vivenciaram um ambiente de inflação elevada. Na 
discussão com a turma consideramos a intervenção do professor importantíssima para enriquecer a leitura e ampliar o conhecimento dos alunos.

As tarefas 3 e 4 podem ser trabalhadas em aproximadamente 50 minutos, contudo para melhor aproveitamento das discussões, o professor poderá optar por dois encontros de aproximadamente 30 minutos com os alunos, um para cada tarefa.

No último encontro, com duração de 50 minutos, sugerimos as tarefas 5 e 6 e apresentamos a tarefa 7 , sendo esta última uma atividade extraclasse.

A tarefa 5 intitulada "Atualizando os gastos mensais" tem como objetivo analisar a tomada de decisão dos alunos perante a desvalorização do salário do personagem Lucas. Confira:

\section{Tarefa 5: Atualizando os gastos mensais}

Lucas é solteiro, tem 19 anos, mora em Juiz de Fora e conseguiu seu primeiro emprego em uma empresa. Em março ele recebeu um aumento de salário e passou a ganhar R\$ 1500,00. Ele sabe que este salário será fixo até março do ano seguinte, mas mesmo assim, resolveu sair de casa e dividir um apartamento com seus amigos a partir do mês de abril. Para ter melhor controle de suas despesas ele fez uma planilha com os gastos mensais do primeiro mês na nova vida fora de casa e continuará fazendo ao longo dos meses. Observe sua planilha:

\begin{tabular}{|l|r|l|}
\hline \multicolumn{1}{|c|}{ Despesas } & Abril & Maio \\
\hline Academia (musculação) & $\mathrm{R} \$ 45,00$ & \\
\hline Condução & $\mathrm{R} \$ 84,00$ & \\
\hline Café na padaria & $\mathrm{R} \$ 105,00$ & \\
\hline Almoço na rua $\$ 240,00$ & \\
\hline Aluguel + condomínio & $\mathrm{R} \$ 300,00$ & \\
\hline Saída (cinema + balada) & $\mathrm{R} \$ 250,00$ & \\
\hline Total & & \\
\hline
\end{tabular}

O que ele não sabia é que a inflação de preços no país a partir do mês de março estaria em torno de $9,2 \%$ ao mês e, como consequência, todos os bens e serviços sofreriam um aumento em torno de $10 \%$ porque os comerciantes não queriam ter perda nos lucros.

Considere que todos os preços do orçamento do Lucas sofreram um aumento 
de $10 \%$ ao mês e responda:

a) Qual a perda em reais do salário do Lucas em maio em relação a abril?

b) Lucas estava pensando em comprar uma moto e, em março, após consultar uma agência viu que se realizasse a compra parcelada em 12 vezes a prestação naquele mês seria de $\mathrm{R} \$ 350,00$. Como esse valor também sofreria $10 \%$ de aumento, essa nova prestação caberia no seu orçamento de abril e maio?

Para a realização desta tarefa consideramos importante o professor realizar uma breve revisão do conteúdo porcentagem e destacar para os alunos que se trata de uma situação fictícia e que os índices de inflação no Brasil são bem distintos do que o apresentado na tarefa. O uso da calculadora não prejudica o desenvolvimento da proposta, porém durante a apresentação do conteúdo consideramos interessante a ideia de estimular os alunos a realizarem o cálculo mental por se tratar de porcentagens básicas. É importante destacar que a discussão proporcionada em torno da situação fictícia é muito mais importante do que somente apresentar cálculos corretos.

A tarefa 6 tem por objetivo apresentar aos alunos cenários presentes no cotidiano de duas famílias: uma que viveu numa época de hiperinflação e outra que vive com a inflação sobre controle. Veja a proposta a seguir:

\section{Tarefa 6: Épocas distintas}

Em 1993 a inflação de preços no mês de março foi de 42,68\%. No mesmo mês em 2014, a inflação foi de $0,92 \%$.

Para conversamos sobre algumas diferenças entre essas duas épocas, colocamos abaixo falas de alguns membros de duas famílias - Silva e Oliveira - com as mesmas características: tinham 3 filhos adolescentes, os pais trabalhavam e as duas famílias moravam de aluguel. As falas relacionadas à família Silva foram anotadas no ano de 1993, e as da família Oliveira ocorreram recentemente, no ano de 2014.

Tente descobrir, pelos comentários abaixo, de qual família é a pessoa que fala:

José: Em reunião de família, resolvemos comprar nossa casa própria financiada porque o país passa por um momento de estabilidade na economia.

Julia: Todo mês, assim que recebo o salário, vamos correndo ao supermercado fazer a compra do mês e estocamos produtos que estão com bons preços.

Cláudia: Meu pai disse que nenhuma empresa estrangeira quer vir para o Brasil porque a gente está devendo muito ao FMI.

Fábio: Nossa família está juntando dinheiro para uma viagem de férias e já sabemos, 
mais ou menos, quanto vamos gastar.

Joana: Hoje eu estava no supermercado e a coisa que mais se via era os funcionários remarcando os preços das mercadorias.

Ricardo: Eu observo que meus pais, apesar de tentarem, não conseguem fazer nosso planejamento financeiro familiar. Parece que isso atrapalha meu pai a tomar decisões.

Esperamos que as justificativas utilizadas para responder aos comentários presentes na tarefa sejam influenciadas pelas leituras e discussões das tarefas anteriores. Ainda existe uma enorme possibilidade de que as respostas aos comentários estejam vinculadas às decisões financeiras presentes no cotidiano das famílias dos alunos.

Nesta tarefa consideramos essencial a intervenção do professor para expor aos alunos informações sobre o papel do FMI (Fundo Monetário Internacional) e também esclarecer possíveis dúvidas sobre os anos de hiperinflação vividos no Brasil na década de 80 e 90.

A tarefa 7 intitulada "Para investigar" foi criada com o intuito de promover nos alunos um momento de pesquisa e reflexão sobre o que foi debatido nos encontros anteriores. Esperamos que esta reflexão seja compartilhada principalmente com alguns membros da família que provavelmente sentiram no dia a dia as consequências da hiperinflação no Brasil nas décadas de 80 e início da década de 90 .

Para isso, elaboramos uma tarefa extraclasse para que os estudantes pensassem sobre o assunto em questão.

\section{Tarefa 7: Para investigar}

Steve tem 14 anos, mora nos Estados Unidos e pretende vir ao Brasil através de um intercâmbio e estudará em sua sala de aula no ano que vem. Só que ele assistiu uma reportagem de quando os brasileiros viviam em uma inflação muito alta no período de 1990 a 1994 e ficou preocupado se seus pais poderiam mantê-lo vivendo aqui por um ano. Envie um e-mail para ele explicando que as coisas são diferentes hoje e comente sobre nossa inflação para que ele tenha informações interessantes para conversar com seus pais.

Propomos aos professores instigar seus alunos a realizar uma pesquisa mais profunda sobre o tema. Esta não deve ficar restrita a buscas na internet, consideramos interessante incentivar a troca de informações do aluno com os membros da família. É importante ressaltar que esta tarefa não deve terminar com o envio do e-mail, ela pode ser bastante discutida em sala de aula. 
Ao propor estas tarefas para a sala de aula, chamamos a atenção para a necessidade de cuidados em relação a postura do professor e também na do aluno. O professor deve entender que estas tarefas devem ser investigativas promovendo uma discussão entre os diferentes modos de pensar dos alunos. Caso se utilize as tarefas como exercícios rotineiros, resolvidos pelo professor na lousa, toda a potencialidade da tarefa ficará perdida e os objetivos para os quais foram criadas - por exemplo, estimular o debate de ideias - ficarão prejudicados. O aluno, por sua vez, deverá ser orientado a mudar sua postura de buscar respostas prontas, únicas, baseadas na cultura do "certo" e do "errado" do ensino tradicional.

É importante observar que essas tarefas também têm como objetivo exercitar a leitura e interpretação dos estudantes e, como consequência, estimulá-los a falar sobre o que entenderam daquilo que foi apresentado.

\section{Referências}

VITAL, M. C. Educação Financeira e Educação Matemática: Inflação de Preços. 199 f. Dissertação (Mestrado Profissional em Educação Matemática). Universidade Federal de Juiz de Fora, Minas Gerais, 2014.

VITAL, M. C. Educação Financeira e Educação Matemática: Inflação de Preços. 41 f. Produto Educacional (Mestrado Profissional em Educação Matemática). Universidade Federal de Juiz de Fora, Minas Gerais, 2014. 